SUPPORTING INFORMATION

\title{
Formation of Alkanethiolate-Protected Gold Clusters with Unprecedented Core Sizes in Thiolation of Polymer-Stabilized Gold Clusters
}

Hironori Tsunoyama, ${ }^{\dagger}$ Patricia Nickut, ${ }^{\ddagger}$ Yuichi Negishi, ${ }^{\dagger}$ Katharina Al-Shamery, ${ }^{\ddagger}$ Yoshiyasu Matsumoto, ${ }^{\dagger}$ and Tatsuya Tsukuda ${ }^{*,+\S}$

${ }^{\dagger}$ Research Center for Molecular-Scale Nanoscience, Institute for Molecular Science, Myodaiji, Okazaki 444-8585, Japan. Institute for Pure and Applied Chemistry, Carl von Ossietzky University of Oldenburg, P.O. Box 2503, D-26111 Oldenburg, Germany. ${ }^{8}$ CREST, Japan Science and Technology Agency, Kawaguchi, Saitama 332-0012, Japan.

Chromatograms of $\mathrm{Au}: \mathrm{SC}_{18}$

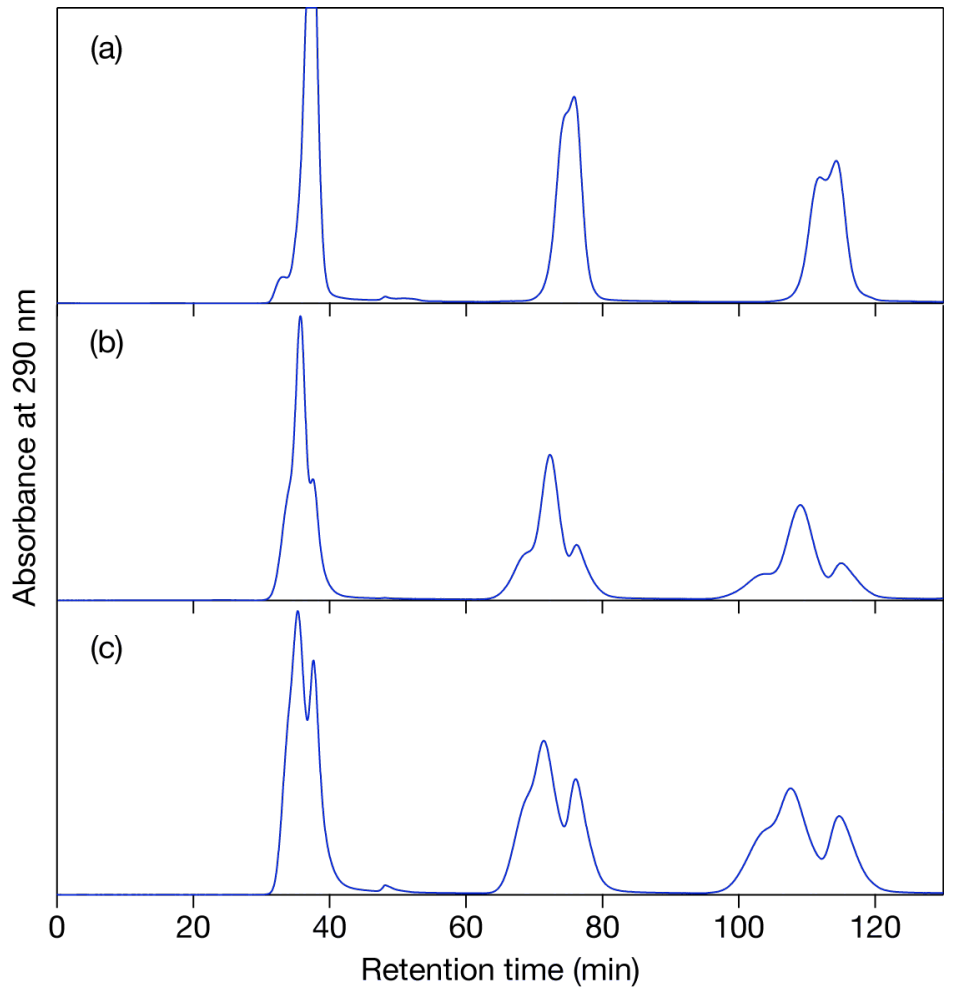

Figure S1. Chromatograms of $\mathrm{Au}: \mathrm{SC}_{18}$ 1-3. 


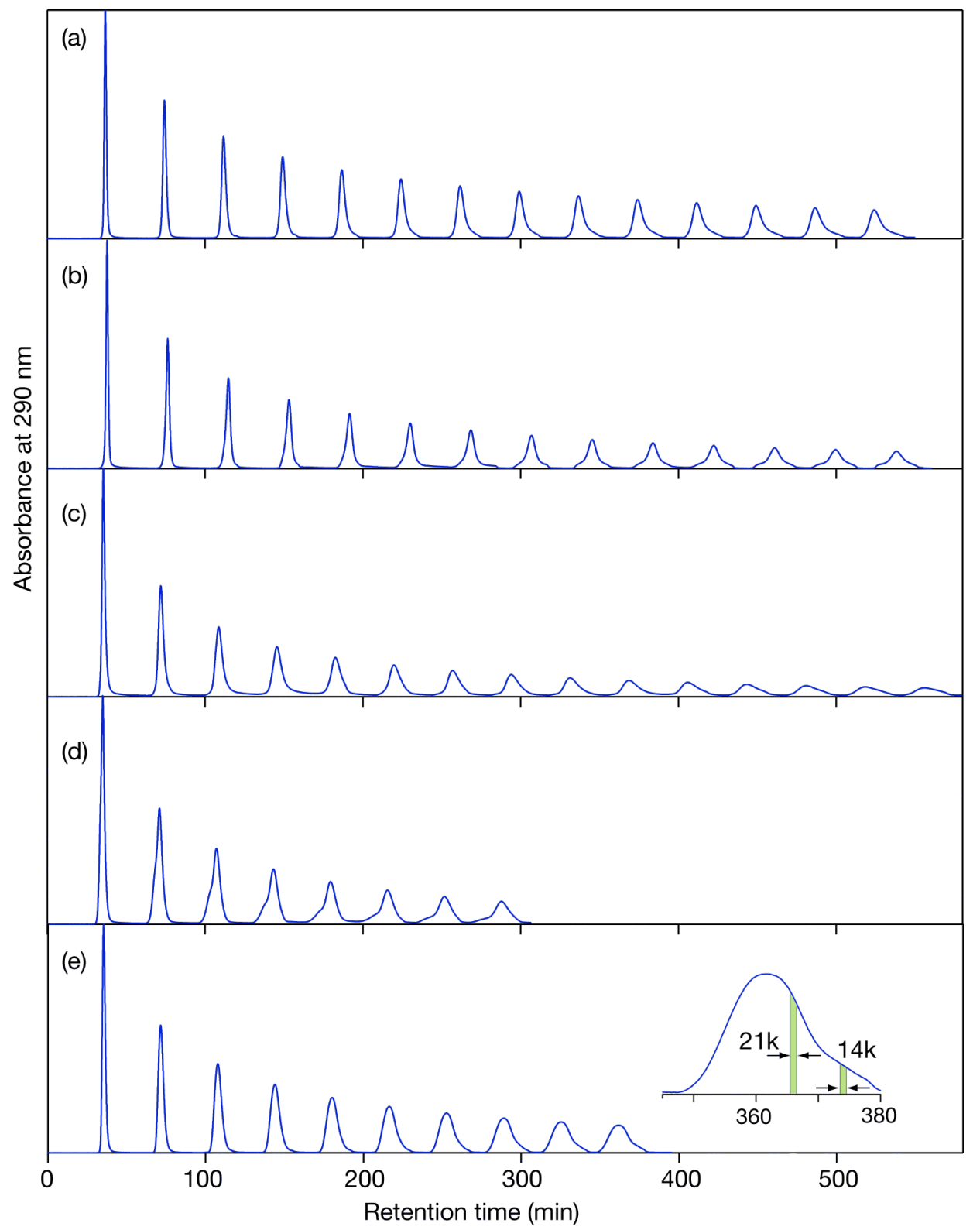

Figure S2. Chromatograms of fractions A-D (a-d) and sample 4 (e). 